\title{
Angiotensinogen gene M235T polymorphism and risk of coronary artery disease: A meta-analysis
}

\author{
YU-JING WANG ${ }^{1 *}$ and YAN PAN ${ }^{2 *}$ \\ ${ }^{1}$ Cardiovascular Department and ${ }^{2}$ Department of Pediatrics, The First Affiliated Hospital of Yangtze University, \\ Medical College of Yangtze University, Shashi District, Jingzhou, Hubei 434000, P.R. China
}

Received March 19, 2012; Accepted July 12, 2012

DOI: $10.3892 / \mathrm{mmr} .2012 .1011$

\begin{abstract}
The angiotensinogen (AGT) gene M235T polymorphism has been suggested to be linked with susceptibility to coronary artery disease (CAD). In the present study, a metaanalysis was performed to assess the correlation between the M235T polymorphism and CAD. Nine studies with a total of 2281 subjects were selected for inclusion in the analysis. The references were retrieved via PubMed, China National Knowledge Infrastructure, Wanfang and VIP database (1995.1-2012.1). The analyses were performed using STATA 10.0 software. Odds ratios (OR) with $95 \%$ confidence intervals (CIs) were assessed after the collected data were pooled for analysis. A significant association was detected between M235T gene polymorphism and CAD in the population studied. The estimates (OR) of CAD risk were calculated in a homozygote comparison $(\mathrm{OR}=1.54 ; 95 \% \mathrm{CI}, 1.09-2.16)$, a heterozygote comparison $(\mathrm{OR}=1.30 ; 95 \% \mathrm{CI}, 1.07-1.58)$, a dominant model $(\mathrm{OR}=0.72 ; 95 \% \mathrm{CI}, 0.55-0.94)$ and a recessive model $(\mathrm{OR}=1.37$; 95\% CI, 0.98-1.91). The current meta-analysis suggests that the M235T polymorphism is associated to an increased risk of CAD.
\end{abstract}

\section{Introduction}

Coronary artery disease (CAD) is a public health issue (1). Moran et al predicted that aging and population growth is likely to increase the incidence of CAD by more than a half over the next 20 years and that projected unfavorable trends in blood pressure, diabetes, total cholesterol and body mass index may accelerate the process. National policy in China has been aimed at controlling cigarette smoking, blood pressure and other risk factors which would counteract the predicted future

Correspondence to: Dr Yu-Jing Wang, Cardiovascular Department, the First Affiliated Hospital of Yangtze University, Hangkong Road 8, Shashi District, Jingzhou, Hubei 434000, P.R. China

E-mail:wyj312@hotmail.com

*Contributed equally

Key words: angiotensinogen gene, Chinese, coronary artery disease, meta-analysis, polymorphism of a CAD epidemic (2). The renin-angiotensin system (RAS) is known to be involved in the development of CAD, and an angiotensinogen (AGT, a component of RAS) gene polymorphism has been identified as a CAD risk. The results, however, have been inconsistent. The M235T SNP is a methionine (Met) to threonine (Thr) amino acid substitution at codon 235 designated as $\mathrm{M}$ and $\mathrm{T}$ alleles, respectively. Previous meta-analyses have indicated that the M235T polymorphism is correlated with an increased risk of CAD $(3,4)$. However, the meta-analysis included only limited articles with Chinese ancestry since the most relevant studies were published using the Chinese language in local journals. Therefore, the association between the M235T polymorphism and CAD among the Chinese Han population should be clarified. The present study investigated whether or not the M235T polymorphism is associated with CAD risk among the Chinese by performing a meta-analysis of the data from the literature.

\section{Materials and methods}

Selection of studies. A comprehensive systematic search was conducted by two independent reviewers (YJW and YP). A search through the electronic databases including PubMed, China National Knowledge Infrastructure, Wanfang and VIP database was conducted for studies using the key words 'coronary artery disease', 'angiotensinogen', 'M235T' and 'gene polymorphism' for relevant citations. The reference lists of retrieved reviews and articles were manually screened. The publication language was restricted to English or Chinese. The literature search was updated on 30 January 2012.

Selection criteria. The selection criteria used to determine which studies were eligible included: i) evaluating the association of M235T polymorphisms in the AGT gene with CAD; ii) using case-control design; iii) studies containing sufficient data; iv) the genotype distribution among the control population was required to be in Hardy-Weinberg equilibrium (HWE).

Data extraction. The following information was extracted from the eligible studies: i) name of the first author; ii) year of publication; iii) region; iv) end point of assessment; v) control status; vi) sample size of subjects with and without CAD; vii) genotype distribution of subjects with and without CAD; and viii) $\mathrm{P}$-value for HWE test in subjects without CAD. 
Table I. Characteristics of the included studies for meta-analysis.

\begin{tabular}{|c|c|c|c|c|c|c|c|c|c|c|c|c|}
\hline \multirow[b]{2}{*}{ Study included } & \multirow[b]{2}{*}{ Area } & \multirow{2}{*}{$\begin{array}{l}\text { End } \\
\text { point }\end{array}$} & \multirow{2}{*}{$\begin{array}{l}\text { Source of } \\
\text { controls }\end{array}$} & \multirow[b]{2}{*}{ Cases } & \multirow[b]{2}{*}{ Controls } & \multicolumn{3}{|c|}{$\begin{array}{c}\text { Genotypes } \\
\text { for cases }\end{array}$} & \multicolumn{3}{|c|}{$\begin{array}{l}\text { Genotypes } \\
\text { for controls }\end{array}$} & \multirow{2}{*}{$\begin{array}{c}\text { HWE } \\
\text { test }\end{array}$} \\
\hline & & & & & & MM & MT & $\mathrm{TT}$ & MM & MT & $\mathrm{TT}$ & \\
\hline Ko et al, 1997 (9) & Taiwan & CAD & Hospital-based & 268 & 338 & 6 & 36 & 225 & 4 & 54 & 279 & 0.45 \\
\hline Chen et al, 1998 (10) & Shanghai & MI & Population-based & 57 & 76 & 4 & 13 & 40 & 13 & 31 & 32 & 0.26 \\
\hline Sheu et al, 1998 (11) & Taiwan & CAD & Population-based & 102 & 145 & 1 & 26 & 75 & 1 & 37 & 107 & 0.25 \\
\hline Xie et al, 2001 (12) & Anhui & CAD & Hospital-based & 106 & 86 & 8 & 29 & 69 & 11 & 30 & 45 & 0.11 \\
\hline Zhu et al, 2002 (13) & Nanjing & CAD & Hospital-based & 118 & 106 & 14 & 48 & 56 & 10 & 42 & 54 & 0.66 \\
\hline Gu et al, 2003 (14) & Nantong & CAD & Population-based & 129 & 90 & 12 & 31 & 86 & 7 & 30 & 53 & 0.36 \\
\hline Zhu et al, 2004 (15) & Beijing & CAD & Hospital-based & 192 & 98 & 12 & 75 & 105 & 8 & 36 & 54 & 0.59 \\
\hline Li et al, 2004 (16) & Henan & CAD & Population-based & 120 & 80 & 11 & 60 & 49 & 14 & 41 & 25 & 0.69 \\
\hline Ren et al, 2005 (17) & Shanxi & CAD & Hospital-based & 100 & 70 & 9 & 24 & 67 & 13 & 26 & 31 & 0.09 \\
\hline
\end{tabular}

HWE, Hardy-Weinberg equilibrium; CAD, coronary artery disease; MI, myocardial infarction.

Statistical analysis. The association of M235T polymorphisms in the AGT gene with CAD was estimated by calculating the pooled odds ratio (OR) and $95 \%$ confidence interval $(\mathrm{CI})$ under a homozygote comparison (TT vs. MM), a heterozygote comparison (TT vs. MT), a dominant model (MM+MT vs. TT) and a recessive model (TT+MT vs. MM). The significance of the pooled OR was determined by Z-test. $\mathrm{P}<0.05$ was considered to indicate a statistically significant result. Q-testing was performed to evaluate whether the variation was due to heterogeneity or chance, with $\mathrm{I}^{2}$ values of 25,50 and $75 \%$ being defined as low, moderate and high estimates, respectively (5). If heterogeneity was observed among the studies, the pooled OR was estimated by the fixed-effects model $(\mathrm{P}>0.10$ or $\mathrm{I}^{2}<50 \%$ ) (6), otherwise, the random-effects model was used to estimate the pooled OR. Sensitivity analyses were conducted to evaluate the stability of the results (7). Publication bias was assessed by Begg's test $(\mathrm{P}<0.05$ was considered to indicate a statistically significant result) (8). Data analysis was performed using STATA version 10.0 (Stata Corporation, College Station, TX, USA).

\section{Results}

Characteristics of the studies. There were 68 articles relevant to the search words. Through screening the title and reading the entire article, nine eligible papers were selected for additional analysis. The flow diagram of reviews shows the detailed process of selection (Fig. 1). The total data of the nine studies were gathered from 1192 CAD patients and 1089 controls in the Chinese Han population. All the included studies for M235T polymorphism were in HWE in controls. Of the nine retrospective studies, four used population-based controls and five used hospital-based controls (Table I). All but one study investigated the myocardial infarction risk.

Results of the meta-analysis. In this AGT M235T gene polymorphism meta-analysis, the results were calculated in a homozygote comparison $(\mathrm{OR}=1.54$; 95\% CI, 1.09-2.16; $\mathrm{P}=0.13$ for heterogeneity; Fig. 2A), a heterozygote comparison

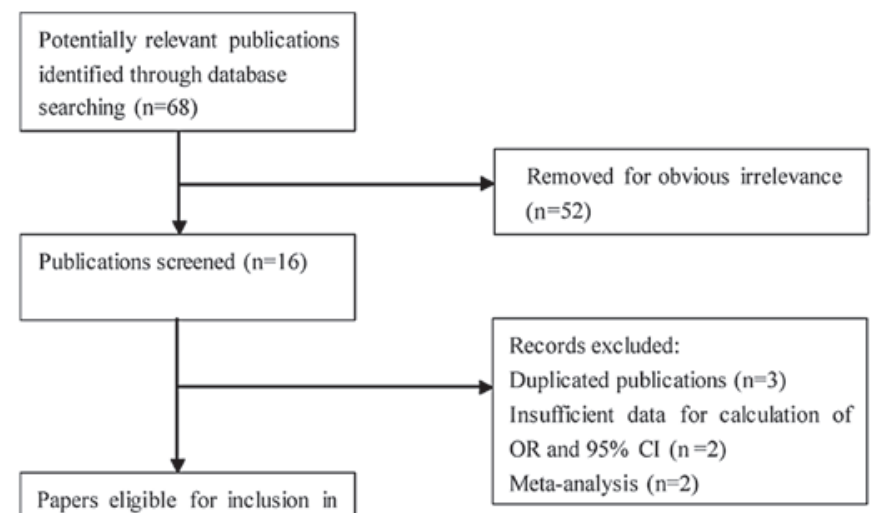

meta-analysis $(\mathrm{n}=9)$

Figure 1. Flow diagram of literature search and selection process. OR, odds ratio; $\mathrm{CI}$, confidence intervals.

$(\mathrm{OR}=1.30 ; 95 \% \mathrm{CI}, 1.07-1.58 ; \mathrm{P}=0.16$ for heterogeneity; Fig. 2B), a dominant model (OR=0.72; 95\% CI, 0.55-0.94; $\mathrm{P}=0.04$ for heterogeneity, by random effects model; Fig. 2C) and a recessive model $(\mathrm{OR}=1.37 ; 95 \% \mathrm{CI}, 0.98-1.91 ; \mathrm{P}=0.34$ for heterogeneity; Fig. 2D). These results suggest that the AGT gene M235T polymorphism is correlated with the increased risk of CAD in the Chinese Han population. Sensitivity analysis was performed for various comparisons in all the subgroups, when one study (13) was excluded, the results revealed no statistical significance and results of the meta-analysis were credible (Table II). Begg's test was used to assess the publication bias, however, no publication bias was detected in these studies (Table II).

\section{Discussion}

CAD is the second leading cause of cardiovascular mortalities in China. Although mortality from CAD is relatively low compared with Western levels, the burden of CAD has been increasing (18). This is partly due to the increase in total choles- 
A

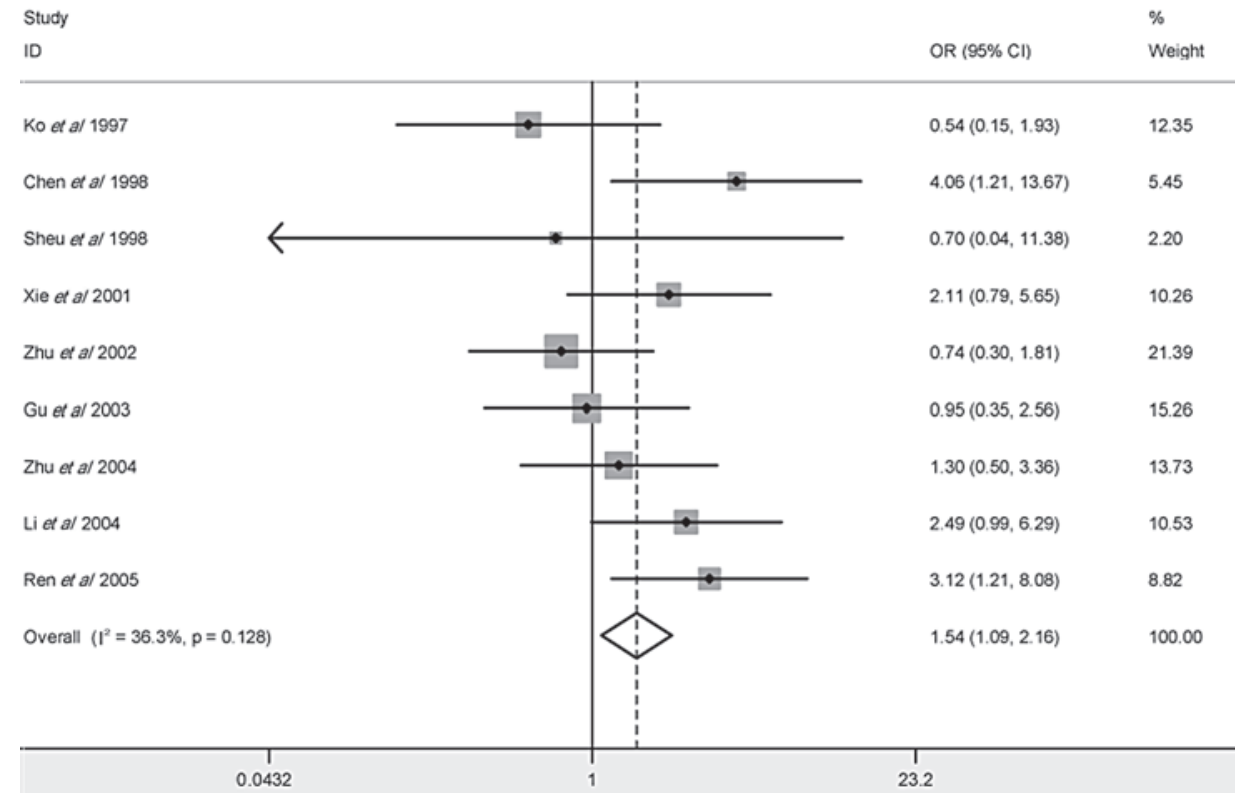

B

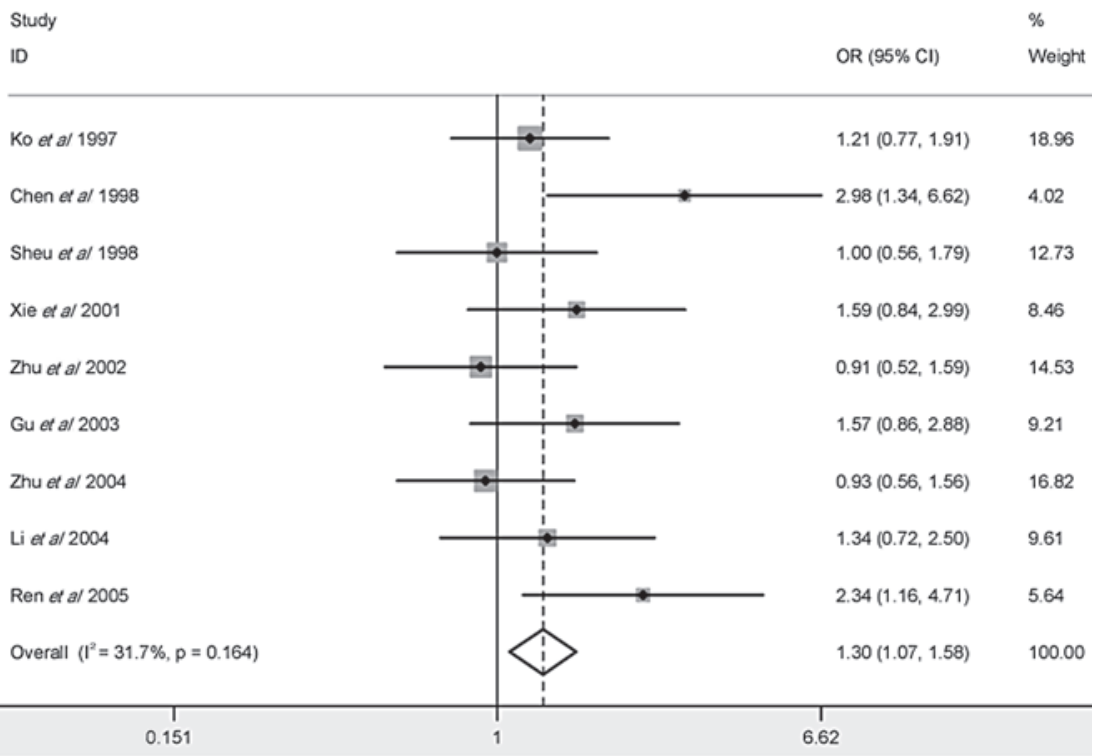

C

\begin{tabular}{|c|c|c|}
\hline $\begin{array}{l}\text { Study } \\
\text { ID }\end{array}$ & OR $(95 \% \mathrm{Cl})$ & $\begin{array}{l}\% \\
\text { Weight }\end{array}$ \\
\hline Koet a/ 1997 & $0.90(0.58,1.39)$ & 13.90 \\
\hline Chen ef a/ 1998 & $0.31(0.15,0.64)$ & 8.35 \\
\hline Shevet $a / 1998$ & $1.01(0.57,1.80)$ & 10.88 \\
\hline Xie ef $a / 2001$ & $0.59(0.33,1.05)$ & 10.75 \\
\hline Zhu ef al 2002 & $1.15(0.68,1.94)$ & 11.88 \\
\hline Guet $a / 2003$ & $0.72(0.41,1.25)$ & 11.23 \\
\hline Zhuet $a / 2004$ & $1.02(0.62,1.66)$ & 12.65 \\
\hline Liet a/2004 & $0.66(0.36,1.20)$ & 10.47 \\
\hline Ren $e$ a/2005 & $0.39(0.21,0.73)$ & 9.89 \\
\hline Overall (1-squared $=51.3 \%, p=0.037$ ) & $0.72(0.55,0.94)$ & 100.00 \\
\hline NOTE: Weights are from random-effects analysis & & \\
\hline $\begin{array}{c}1 \\
0.149\end{array}$ & $\begin{array}{l}T \\
6.7\end{array}$ & \\
\hline
\end{tabular}

Figure 2. Meta-analysis of the relationship between the M235T polymorphism and CAD risk using (A) a homozygote comparison, (B) a heterozygote comparison and $(\mathrm{C})$ a dominant model. CAD, coronary artery disease; OR, odds ratio; $\mathrm{CI}$, confidence intervals. 
D

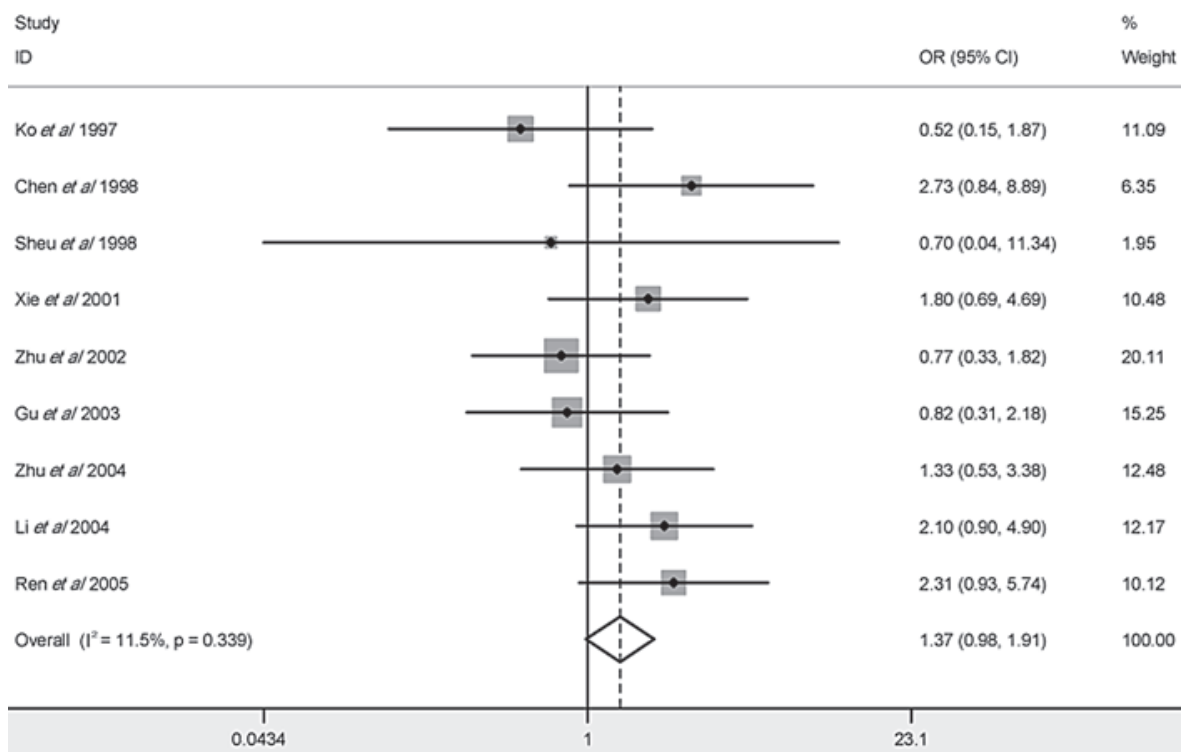

Figure 2. Continued. Meta-analysis of the relationship between the M235T polymorphism and CAD risk using (D) a recessive model. CAD, coronary artery disease; OR, odds ratio; $\mathrm{CI}$, confidence intervals.

Table II. Summary ORs and 95\% CI of the included studies for meta-analysis.

\begin{tabular}{|c|c|c|c|c|c|c|c|c|c|c|c|}
\hline \multirow{2}{*}{$\begin{array}{l}\text { Genetic } \\
\text { model }\end{array}$} & \multicolumn{2}{|c|}{$\begin{array}{l}\text { Sample } \\
\text { size }\end{array}$} & \multirow{2}{*}{$\begin{array}{l}\text { Type of } \\
\text { model }\end{array}$} & \multicolumn{2}{|c|}{$\begin{array}{c}\text { Test of } \\
\text { heterogeneity }\end{array}$} & \multicolumn{2}{|c|}{$\begin{array}{c}\text { Test of } \\
\text { association }\end{array}$} & \multicolumn{2}{|c|}{$\begin{array}{c}\text { Test of } \\
\text { publication bias }\end{array}$} & \multicolumn{2}{|c|}{$\begin{array}{l}\text { Sensitivity } \\
\text { analysis }\end{array}$} \\
\hline & Case & Control & & $\mathrm{I}^{2}$ & P-value & OR & $95 \%$ CI & Z & P-value & OR & $95 \% \mathrm{CI}$ \\
\hline TT vs. MM & 1192 & 1089 & Fixed & $36.3 \%$ & 0.13 & 1.54 & $1.09-2.16$ & 0.10 & 0.20 & 1.76 & $1.21-2.54$ \\
\hline TT vs. MT & & & Fixed & $31.7 \%$ & 0.16 & 1.30 & $1.07-1.58$ & 2.81 & 0.01 & 1.37 & $1.11-1.69$ \\
\hline Dominant model & & & Random & $51.3 \%$ & 0.04 & 0.72 & $0.55-0.94$ & 2.40 & 0.02 & 0.68 & $0.52-0.90$ \\
\hline Recessive model & & & Fixed & $11.5 \%$ & 0.34 & 1.37 & $0.98-1.91$ & 0.73 & 0.47 & 1.52 & $1.06-2.18$ \\
\hline
\end{tabular}

CI, confidence intervals; OR, odds ratio.

terol, reflecting an increasingly 'Western diet' (19) and partly due to an increase in the aged population. RAS plays a key role in regulating blood pressure and the promotion of vascular growth. Chen et al were the first to report the link between the M235T polymorphism and CAD in the Chinese Han population, which carried an approximately 4-fold increased risk of CAD (10). There has been some inconsistency, with certain studies in support of this finding, whereas others were not, suggesting that this polymorphism may serve as a possible risk factor for CAD. In the present meta-analysis, we extracted data from nine eligible studies, including a total of 1192 CAD patients and 1089 controls, the studied population was confined to Chinese individuals with a homogeneous genetic background. Furthermore, all relevant studies published in English or Chinese were included for the meta-analysis, which reduced language biases. Our results suggest that the M235T polymorphism was significantly associated with CAD in the Chinese Han population. The finding was consistent with those from the previous meta-analysis, indicating that the association was significant among Europeans and East Asians (3).

The mechanism of how the AGT gene M235T polymorphism relates to CAD risk is unclear. In a previous study, the serum AGT level was shown to be higher in subjects carrying the $235 \mathrm{~T}$ allele (20). AGT interacts with renin to produce angiotensin II (Ang II). Ang II has been demonstrated in human and animal models to be involved in the development of cardiomyocyte hypertrophy, and in cardiac fibrosis and the modulation of cardiac fibroblast growth and collagen synthesis (21). In addition, Ang II activates vascular cell apoptosis, contributing to vascular remodelling and cardiomyocyte loss in ischaemia-reperfusion and myocardial infarction (22). Stimulation of the AT1 receptor by Ang II is responsible for vasoconstriction, endothelial dysfunction and the occurrence of atherosclerosis (23), their results were heterogeneous, and require further investigation.

However, limitations of the meta-analysis were that the number of studies and the number of subjects in the studies included in the meta-analysis by specific subgroups were small. Therefore, more studies with larger sample sizes are required. Additionally, the effects of gene-gene and gene-environment interactions were not addressed in this meta-analysis.

In conclusion, our results suggest that the AGT gene M235T polymorphism is involved in the susceptibility to CAD, particularly in the Han ethnic group. Due to the limitations 
mentioned, additional investigations should be performed to investigate these associations.

\section{References}

1. Negi S and Anand A: Atherosclerotic coronary heart diseaseepidemiology, classification and management. Cardiovasc Hematol Disord Drug Targets 10: 257-261, 2010.

2. Moran A, Gu D, Zhao D, et al: Future cardiovascular disease in China: Markov model and risk factor scenario projections from the coronary heart disease policy model - China. Circ Cardiovasc Qual and Outcomes 3: 243-252,2010.

3. Xu MQ, Ye Z, Hu FB and He L: Quantitative assessment of the effect of angiotensinogen gene polymorphisms on the risk of coronary heart disease. Circulation 116: 1356-1366, 2007.

4. Zafarmand MH, van der Schouw YT, Grobbee DE, et al: The M235T polymorphism in the AGT gene and CHD risk: evidence of a Hardy-Weinberg equilibrium violation and publication bias in a meta-analysis. PLoS One 3: e2533, 2008.

5. Chen D, Liu JL, Liu Y, et al: Lack of an association between $-308 \mathrm{G}>\mathrm{A}$ polymorphism of the TNF- $\alpha$ gene and liver cirrhosis risk based on a meta-analysis. Genet Mol Res 10: 2765-2774, 2011.

6. Mantel N and Haenszel W: Statistical aspects of the analysis of data from retrospective studies of disease. J Natl Cancer Inst 22: 719-748, 1959

7. DerSimonian R and Laird N. Meta-analysis in clinical trials. Control Clin Trials 7: 177-188, 1986.

8. Egger M, Davey Smith G, Schneider M and Minder C. Bias in meta-analysis detected by a simple, graphical test. BMJ 315: 629-634, 1997.

9. Ko YL, Ko YS, Wang SM, et al: Angiotensinogen and angiotensin-I converting enzyme gene polymorphisms and the risk of coronary artery disease in Chinese. Hum Genet 100: 210-214, 1997.

10. Chen D, Zhang M, Fan W, et al: A molecular variant of angiotensinogen gene is associated with myocardial infarction in Chinese. Zhonghua Yi Xue Yi Chuan Xue Za Zhi 15: 133-135, 1998 (In Chinese).

11. Sheu WH, Lee WJ, Jeng CY, et al: Angiotensinogen gene polymorphism is associated with insulin resistance in nondiabetic men with or without coronary heart disease. Am Heart J 136: 125-131, 1998
12. Xie Y, Zhang FM, Ma WZ, et al: Association between gene polymorphism of renin-angiotensin system and coronary heart disease. Nanjing Yi Ke Da Xue Xue Bao 21: 488-491, 2001 (In Chinese).

13. Zhu TB, Xu W, Yang ZJ, et al: Association analysis of three polymorphism of renin-angiotensin system genes with coronary heart disease. Jiangsu Med J 28: 745-746, 2002 (In Chinese).

14. Gu WD, Zhu JH, Pan M, et al: Effects of angiotensinogen and apolipoprotein $\mathrm{E}$ gene polymorphisms on coronary heart disease. Nan Tong Yi Xue Yuan Xue Bao 23: 394-395, 2003 (In Chinese).

15. Zhu TN, Pan JQ, Shen ZJ, et al: Gene polymorphisms of reninangiotensin system and coronary thrombosis disease. Zhongguo Shi Yan Xue Ye Xue Za Zhi 12: 674-679, 2004 (In Chinese).

16. Li L, Fan XH, Zhang YW, et al: Association between angiotensinogen gene polymorphism and severity of coronary artery stenosis. J Med Forum 25: 12-14, 2004 (In Chinese).

17. Ren J, Jia YP, Lv JY and Guo XH: Relationship between angiotensinogen gene M235T polymorphism and coronary heart disease. J Shanxi Med Univ 36: 439-442, 2005 (In Chinese).

18. Zhang XH, Lu ZL and Liu L: Coronary heart disease in China. Heart 94: 1126-1131, 2008.

19. Critchley J, Liu J, Zhao D, et al: Explaining the increase in coronary heart disease mortality in Beijing between 1984 and 1999. Circulation 110: 1236-1244, 2004.

20. Jeunemaitre X, Soubrier F, Kotelevtsev YV, et al: Molecular basis of human hypertension: role of angiotensinogen. Cell 71: 169-180, 1992.

21. Henrion D, Kubis N and Lévy BI: Physiological and pathophysiological functions of the AT(2) subtype receptor of angiotensin II: from large arteries to the microcirculation. Hypertension 38: 1150-1157, 2001.

22. Horiuchi M, Akishita M and Dzau VJ: Recent progress in angiotensin II type 2 receptor research in the cardiovascular system. Hypertension 33: 613-21, 1999.

23. Dietz R, von Harsdorf R, Gross M, et al: Angiotensin II and coronary artery disease, congestive heart failure, and sudden cardiac death. Basic Res Cardiol 93: 101-108, 1998. 